\title{
Cathepsin B-Mediated NLRP3 Inflammasome Formation and Activation in Angiotensin II -Induced Hypertensive Mice: Role of Macrophage Digestion Dysfunction
}

\author{
Dawei Lian ${ }^{\mathrm{a}}$ Jieqing Lai ${ }^{\mathrm{a}}$ Yanjiao Wu $\mathrm{Wu}^{\mathrm{a}}$ Lei Wang ${ }^{\mathrm{a}}$ Yongjun Chen ${ }^{\mathrm{b}}$ \\ Yang Zhang ${ }^{c}$ Krishna M. Boinic Yi Huang ${ }^{d}$ Yang Chen ${ }^{\mathrm{a}}$ \\ aSchool of Pharmaceutical Science, Guangzhou University of Chinese Medicine, Guangzhou, bSouth \\ China Research Center for Acupuncture and Moxibustion, Guangzhou University of Chinese Medicine, \\ Guangzhou, China, 'Department of Pharmacological \& Pharmaceutical Sciences, College of Pharmacy, \\ University of Houston, Houston, USA, 'Medical Center of Stomatology, The First Affiliated Hospital of \\ Jinan University, Guangzhou, China
}

\section{Key Words}

Hypertension • Angiotensin II • Macrophage digestion • NLRP3 inflammasome $\cdot$ Cathepsin B

\begin{abstract}
Background/Aims: Angiotensin II (Ang II) is an octapeptide hormone that plays a significant role in mediating hypertension. Although hypertension is considered a chronic inflammatory disease, the molecular basis of the sterile inflammatory response involved in hypertension remains unclear. Methods: We investigated the role of macrophage NLRP3 inflammasomes in engulfing and digesting microbes, a key macrophage function, and in early onset of hypertension-associated macrophage injury using biochemical analyses, gene silencing, molecular biotechnology, immunofluorescence, and microbiology. Results: Ang II stimulation decreased nitric oxide (NO) release and macrophage digestion in cultured THP-1 cells and markedly increased NLRP3 inflammasome formation and activation. NO release and macrophage digestion were restored by NLRP3 inflammasome inhibition with isoliquiritigenin and gene silencing. This Ang II-induced upregulation of NLRP3 inflammasomes in macrophages was attributed to lysosomal damage and release of cathepsin B. Mechanistically, losartan, a nonpeptide Ang II receptor antagonist, decreased Ang II-induced NLRP3 inflammasome activation, lysosomal membrane permeability, lysosomal cathepsin B release, and macrophage digestion dysfunction. Similarly, Ang II-induced macrophage microbe digestion and NO production, which were blocked by ATI gene silencing. In addition, in vivo experiments showed that the bacteria scavenging function was clearly decreased in macrophages from Ang II-induced hypertensive mice. Conclusion: Angiotensin II enhances lysosomal membrane
\end{abstract}

D. Lian and J. Lai contributed equally to this work.

\begin{tabular}{ll}
\hline Yang Chen & School of Pharmaceutical Science, Guangzhou University of Chinese Medicine \\
and Yi Huang & Guangzhou (China) \\
& E-Mail ychen8@gzucm.edu.cn; yhuang312@jnu.edu.cn
\end{tabular}


permeabilization and the consequent release of lysosomal cathepsin $B$, resulting in activation of the macrophage NLRP3 inflammasome. This may contribute to NO mediation of dysfunction in digesting microbes.

(C) 2018 The Author(s)

Published by S. Karger AG, Basel

\section{Introduction}

The NLRP3 (nucleotide-binding domain and leucine-rich repeat pyrin domain containing 3 ) inflammasome, which belongs to the nucleotide-binding and oligomerization domain-like receptor (NLR) family, plays a critical role in the pathogenesis of cardiovascular diseases, including hypertension, hypercholesterolemia, and hyperglycemia [1-3]. As a pattern recognition receptor, NLRP3 is upregulated by stimulation with pathogen-associated molecular patterns (PAMPs) [4], which are recruited by the adapter protein apoptosisassociated speck-like protein containing CARD (ASC), and then converts pro-caspase-1 into cle-caspase-1 (cleaved form) [5]. NLRP3 inflammasome activation transforms proinflammatory cytokines such as interleukin (IL)-1 $\beta$ and IL-18 from their immature "pro" forms to their active forms, which have different effects in different cell types, including phenotypic transformation, cell pyroptosis, and cell membrane permeability [6-8]. In macrophages, NLRP3 inflammasome activation is critical in the formation of foam cells and other atherosclerotic lesions in response to proatherogenic stimuli such as cholesterol crystals $[9,10]$. However, it remains unclear whether the activated NLRP3 inflammasomes play a critical role in the macrophage dysfunction induced by angiotensin II (Ang II) stimulation and how activated NLRP3 inflammasomes lead to macrophage injury and ultimately hypertensive complications.

In this regard, Ang II is a component of the intrarenal renin-angiotensin system (RAS) that regulates numerous renal processes such as hemodynamics and transport and that is a key factor in maintaining blood pressure homeostasis [11]. Recent work suggested that an RAS disorder, particularly elevated Ang II, is correlated with increased expression of pro-inflammatory cytokines [12] and reactive oxygen species (ROS), which cause the endothelial dysfunction implicated in hypertension-associated vascular diseases [13, 14]. Indeed, angiotensin receptor blockers have become the first-line medication for the treatment of hypertensive diseases and protect various organs against damage in many hypertensive animal models [15]. Furthermore, there is strong evidence that Ang II induces oxidative stress in macrophages, which is the crucial risk factor for the development of various hypertension-associated pathologies [16]. In addition, macrophage dysfunction is a pathological change induced by risk factors for hypertensive complications [17]. However, the role of Ang II-induced hypertension in NLRP3 inflammasome activation of macrophages remains unknown.

We hypothesized that Ang II-induced NLRP3 inflammasome activation primarily acts through lysosome destabilization-mediated signaling and thereby results in macrophage digestion dysfunction. To test this hypothesis, we first determined whether the NLRP3 inflammasome in macrophages is formed and activated in response to Ang II. We then revealed its role in lysosomal damage and release of cathepsin B in Ang II-induced NLRP3 inflammasome activation and macrophage digestion dysfunction. Using in vivo animal experiments, we examined whether Ang II stimulation was associated with macrophage digestion dysfunction. Our results show that NLRP3 inflammasome activation in macrophages during Ang II stimulation may trigger and promote macrophage digestion dysfunction during hypertension and that lysosomal stabilization is critical for macrophage digestion function due to its ability to inhibit inflammasome activation. 


\section{Cellular Physiology Cell Physiol Biochem 2018;50:1585-1600 \begin{tabular}{l|l|l} 
and Biochemistry Published online: 26 October 2018 & $\begin{array}{l}\text { (c) } 2018 \text { The Author(s). Published by S. Karger AG, Basel } \\
\text { www.karger.com/cpb }\end{array}$ \\
\hline
\end{tabular}}

Lian et al.: Angii Induces Macrophage Digestion Dysfunction

\section{Materials and Methods}

\section{Cell culture and treatment}

The murine macrophage cell line THP-1 was purchased from ATCC (Manassas, Virginia ). The cell line was originally isolated from human monocytic leukemia. THP-1 cells were cultured in RPMI-1640 medium (Gibco, Waltham, MA) supplemented with $100 \mathrm{U} / \mathrm{ml}$ penicillin, $100 \mu \mathrm{g} / \mathrm{ml}$ streptomycin, and $10 \%$ fetal bovine serum (Gibco) at $37^{\circ} \mathrm{C}$ in a $5 \% \mathrm{CO}_{2}$ incubator. For monocyte-macrophage differentiation, THP-1 cells were treated with PMA (Sigma-Aldrich, St. Louis, MO) (50 nM) for $24 \mathrm{~h}$. To stimulate the cells with Ang II (Sigma), the cells were treated with or without Ang II (0.5-10 $\mu \mathrm{M})$ and then incubated for $24 \mathrm{~h}$. In some experiments, the cells were also pretreated with isoliquiritigenin (ISO, $4.4 \mu \mathrm{g} / \mathrm{ml}$ ) , losartan (LOS, $10 \mu \mathrm{M}$ ) or Ca-074 $(10 \mu \mathrm{M})$ for $30 \mathrm{~min}$.

\section{Bacteria and infection}

Escherichia coli BL21 (ATCC BBA-1025) was cultured in LB Broth (Coolaber, China) with 1.5\% Agar (Oxoid, UK) at $37^{\circ} \mathrm{C}$ in an incubator for $24 \mathrm{~h}$. The bacteria were then transferred to phosphate-buffed saline (PBS) before cell infection. Growth density was measured by a McFarland Nephelometer. The infectious dose of bacteria was $3 \times 10^{8}$ bacteria/ml at a McFarland of 1 . The THP- 1 cells were plated at $1 \times 10^{6}$ cells/ $\mathrm{ml}$ and cultured as described above. Then, the cells were infected with $E$. coli (multiplicity of infection [MOI] 100) for $3 \mathrm{~h}$ in serum-free DMEM.

\section{Cell proliferation and cytotoxicity assay}

THP- 1 cells were plated at a density of $1 \times 10^{4}$ cells/well in 96-well plates and incubated in a humidified environment at $37^{\circ} \mathrm{C}$ overnight. The cells were treated with different concentrations of Ang II for $24 \mathrm{~h}$. Cell viability was assessed using a methylthiazol tetrazolium (MTT) assay. The optical density of formazan crystals in the control group was taken as $100 \%$ viability. The cytotoxicity of THP-1 cell exposure to E. coli and Ang II was determined by assessing viable cell counts using YOYO-1 (Invitrogen, Carlsbad, CA). The culture supernatant and remaining THP-1 cells were collected after incubation with E. coli (MOI 100) and Ang II $(10 \mu \mathrm{M})$ for 3 and $24 \mathrm{~h}$, respectively. Cell cultures without bacterial infection or Ang II treatment served as controls. The procedures were performed according to the relevant instruction manuals, and post-infection cells lacking trypan blue staining were directly counted.

\section{Phagocytosis and bacteria killing assays}

THP- 1 cells were pretreated with Ang II for $24 \mathrm{~h}$ followed by E. coli (MOI 100) in serum-free DMEM for $3 \mathrm{~h}$ at $37^{\circ} \mathrm{C}$ in a humidified $5 \% \mathrm{CO}_{2}$ incubator. For phagocytosis assays, the cells were washed three times with PBS to eliminate extracellular bacteria. For bacteria killing assays, the cells were incubated in serumfree DMEM with $200 \mu \mathrm{g} / \mathrm{ml}$ gentamicin after $12 \mathrm{~h}$. To determine bacterial content in the phagocytosis and bacteria killing assays, cells were lysed with $0.1 \%$ saponin for $15 \mathrm{~min}$, serially diluted, plated onto LB agar plates, and incubated at $37^{\circ} \mathrm{C}$ for $18 \mathrm{~h}$. The colony-forming units (CFUs) of bacteria were determined by the number of colonies formed as described previously [18].

\section{Nitric oxide assay}

THP-1 cells were prepared as described above. Nitric oxide (NO) in culture medium was measured by the Griess reaction method. Briefly, the culture supernatants were mixed with Griess reagent (Beyotime, Shanghai, China) for $10 \mathrm{~min}$ at room temperature. The absorbance was measured at $540 \mathrm{~nm}$ using a microplate reader. The nitrite content was expressed as a percentage of the untreated control.

\section{ROS assay}

THP- 1 cells were treated as described above and intracellular ROS was measured by DCFH-DA. Briefly, the cells were washed three times with PBS and incubated with DCFH-DA (1:1000) for $30 \mathrm{~min}$, then digested using $0.25 \%$ trypsin and washed three times with ice-cold DMEM solution to remove the remaining fluorescence dye. The excitation and emission wavelengths used in the flow cytometry were adjusted to 488 and $525 \mathrm{~nm}$. 


\section{Cellular Physiology Cell Physiol Biochem 2018;50:1585-1600 \begin{tabular}{l|l|l} 
and Biochemistry Published online: 26 October 2018 & $\begin{array}{l}\text { (c) } 2018 \text { The Author(s). Published by S. Karger AG, Basel } \\
\text { www.karger.com/cpb }\end{array}$ \\
\hline
\end{tabular}}

\section{Assessment of cellular cathepsin B activity}

Cathepsin B activities in THP-1 cells were determined via measurement of the cleavage of enzymespecific, fluorogenic substrates in cell lysates using commercially available assay kits (BioVision, San Francisco, California). The fluorescent cathepsin B substrate was then used to stain the cells, Hoechst stain was used to label the cell nuclei, and acridine orange was used to identify lysosomes (Enzo, Farmingdale, New York), following the manufacturer's instructions.

\section{Western blot analysis}

Total protein was extracted using RIPA buffer (Thermo Fisher Scientific, Waltham, MA). The supernatant was obtained after centrifugation at $10,000 \times g$ for $15 \mathrm{~min}$ at $4^{\circ} \mathrm{C}$ and its protein concentration was measured with the BCA Protein Assay Kit (Beyotime). Cell homogenates were denatured with reducing Laemmli SDS sample buffer and boiled in a water bath for $5 \mathrm{~min}$ at $95^{\circ} \mathrm{C}$. Equal amounts of the protein samples were separated by $12 \%$ SDS-PAGE and transferred onto PVDF membrane. The membrane was incubated in primary antibodies at $4^{\circ} \mathrm{C}$ overnight and then treated with anti-rabbit IgG (1:2000; Cell Signaling Technology [CST], Danvers, MA) or anti-mouse IgG (1:2000; CST) for $2 \mathrm{~h}$ at room temperature. The primary antibodies were anti-NLRP3 (1:1000; CST), anti-caspase-1 1:625?; Santa, Massachusetts, USA), and anti-ASC (1:2000; 1:625; Santa). Anti- $\beta$-actin (1:1000; Boster, Beijing, China) was used as an internal control. The target bands were detected and analyzed using ImageJ software (National Institutes of Health, Bethesda, MD).

\section{Immunofluorescence microscopic analysis}

THP-1 cells adherent to round glass coverslips were fixed with $4 \%$ buffered paraformaldehyde and permeabilized with $0.1 \%$ Triton X-100. Then, the cells were stained using goat anti-NLRP3 (1:200; Abcam, Cambridge, UK), mouse anti-caspase-1 (1:200; Santa, Massachusetts, USA), or rabbit anti-ASC (1:100, Santa). After incubation with primary antibodies, the samples were washed and labeled with the corresponding Alexa Fluor-488- and Alexa Fluor-555-conjugated secondary antibodies (Invitrogen). The cells were visualized with a Zeiss LSM800 microscope (Oberkochen, Germany). Colocalization was analyzed by Image Pro Plus software, and the colocalization coefficient is presented as the Pearson's correlation coefficient.

\section{RNA isolation and real-time quantitative PCR}

Total RNA was isolated from the cells with RNAiso Plus (Takara, Kusatsu, Japan) and the concentration of extracted RNA was measured spectrophotometrically at $260 \mathrm{~nm}$. The RNA quality was assessed by the ratio of absorbance at 260 and $280 \mathrm{~nm}$; A260/A280 values from 1.9 to 2.1 were considered acceptable. Total RNA was reverse transcribed into cDNA using a PrimeScript RT reagent kit with gDNA Eraser (Takara). Real-time PCR was performed with SYBR Green (Takara) following the manufacturer's instructions. The primers were synthesized as follows: 5'-AGGAGAATGGACCTGCAAGC-3' (forward primer) and 5'-TCTACCATCATCCAGCCTTGG-3' (reverse primer) for the mouse NLRP3 gene; 5'-GGCGAGAGAGGTGAACAAGG-3' (forward primer) and 5'-GCCAAGGTCTCCAGGAACAC-3' (reverse primer) for the mouse caspase-1 gene; 5'-GGCGAGAGAGGTGAACAAGG-3' (forward primer) and $5^{\prime}$-GCCAAGGTCTCCAGGAACAC-3' (reverse primer) for the mouse ASC gene; and 5'-CCCATCTATGAGGGTTACGC-3' (forward primer) and 5'-TTTAATGTCACGCACGATTTC-3' (reverse primer) for $\beta$-actin (used as an internal reference control). The reactions were run at $50^{\circ} \mathrm{C}$ for 2 min and $95^{\circ} \mathrm{C}$ for $10 \mathrm{~min}$, followed by 45 cycles at $95^{\circ} \mathrm{C}$ for $15 \mathrm{~s}$ and $60^{\circ} \mathrm{C}$ for $1 \mathrm{~min}$ on an Applied Biosystems Step-One Fast Real-Time PCR system. The results were quantified using the $2^{-\Delta \Delta C T}$ method.

\section{Plasmid construction and nucleofection}

The gRNA sequences for the CRISPR/Cas9 genes of NLRP3 and ATR1 were designed by the CRISPR Design tool (http://crispr.mit.edu/). Then, the NLRP3 and ATR1 gRNA sequences (the NLRP3 gRNA sequence was 5'-GACGAGTGTCCGTTGCAAGC-3' and ATR1 gRNA sequence was 5'-CTTTCTTCTAAATCTCGCCC-3') were synthesized and inserted into the BbsI-digested px459 plasmid. Gene editing in cells was performed by Lipofectamine 3000 transfection according to the manufacturer's instructions (Invitrogen). Briefly, THP-1 cells were spread to more than $80 \%$ confluency and incubated in serum-free DMEM for $30 \mathrm{~min}$. The plasmid master mix was prepared by dilution in Opti-MEM ${ }^{\mathrm{TM}}$ Medium (Gibco). P3000 ${ }^{\mathrm{TM}}$ and Lipofectamine ${ }^{\mathrm{TM}} 3000$ reagent were then added for $15 \mathrm{~min}$ at room temperature. The transfected cells were incubated in medium 


\section{Cellular Physiology Cell Physiol Biochem 2018;50:1585-1600 \begin{tabular}{l|l|l} 
and Biochemistry Published online: 26 October 2018 & $\begin{array}{l}\text { (c) } 2018 \text { The Author(s). Published by S. Karger AG, Basel } \\
\text { www.karger.com/cpb }\end{array}$ \\
\hline
\end{tabular}}

Lian et al:: Angii Induces Macrophage Digestion Dysfunction

with $2.5 \mu \mathrm{g} / \mathrm{ml}$ puromycin to screen out the gRNA plasmid-containing cells and the cellular transfection efficiency of cells was analyzed by western blot.

\section{Animal procedures}

Male C57BL/6N mice (8 weeks of age) weighing approximately 20-22 g were purchased from Vital River Laboratory Animal Technology Co. (Beijing, China). The mice were housed in individual ventilated cages and received food and water. The laboratory temperature was $25 \pm 2{ }^{\circ} \mathrm{C}$, the relative humidity was $50 \% \pm 5 \%$, and the animals were maintained on a $12 \mathrm{~h} / 12 \mathrm{~h}$ light/dark cycle. The mice were housed for 7 days to adapt to the environment before experimentation. The mice were anesthetized with $10 \% \mathrm{w} / \mathrm{v}$ chloral hydrate by peritoneal injection for subcutaneous implantation of an osmotic mini-pump (Alzet 1007D; Charles River, Wilmington, MA) delivering 1.5 ng Ang II (Sigma) per minute and per gram body weight or a sham implantation for 5 days as described [19]. The mice were trained daily before the operation to have blood pressure determined with a computerized tail cuff system (BP-2000; Apex, New York, USA). Blood pressure was measured in conscious mice via the tail cuff, with three measurements per animal for each recording [20].

\section{In vivo scavenging bacteria assay}

Live E. coli liquid was prepared with aseptic saline and injected into the mouse tail vein at a bacterial concentration of $2 \times 10^{7} \mathrm{CFU} / \mathrm{g}$. Three hours later, cardiac blood was extracted and mononuclear cells were isolated by density gradient centrifugation. Briefly, the blood sample was layered onto Ficoll-Paque PLUS (Miltenyi Biotec, Gladbach, Germany) and centrifuged at $400 \mathrm{~g}$ for $30 \mathrm{~min}$ at $18^{\circ} \mathrm{C}$. Then, the upper layer was removed and the lymphocyte layer was transferred according to the manufacturer's instructions. The lymphocytes were lysed with $0.1 \%$ saponin for $15 \mathrm{~min}$, serially diluted, plated onto LB agar plates, and incubated at $37^{\circ} \mathrm{C}$ for $18 \mathrm{~h}$. CFUs of bacteria were determined by the number of colonies formed [21].

\section{Statistical analysis}

Results were expressed as mean \pm SEM and analyzed using SPSS 21.0. The LSD test or Dunnett's test was used for multiple groups based on homogeneity of variance. $\mathrm{P}<0.05$ indicated statistical significance.

\section{Results}

\section{Ang II treatment affects macrophage digestion function and NO release}

Macrophages are cells of the innate NO synthase/ROS system [22]. The cytotoxicity of THP-1 cells incubated with E. coli (MOI 100) and Ang II $(10 \mu \mathrm{M})$ was determined by assessment of viable cell counts using YOYO-1; the cytotoxicity of the cells was not different from that of control cells after $3 \mathrm{~h}$ (Fig. $1 \mathrm{~A}$ and $\mathrm{B}$ ). In addition, the proliferation of THP-1 cells incubated with Ang II $(0-20 \mu \mathrm{M})$ was not significantly different after $24 \mathrm{~h}$, as determined by the MTT method (Fig. 1C). However, LDH leakage and cell death significantly increased with incubation with E. coli and Ang II for $24 \mathrm{~h}$ (data not shown). NO production was significantly decreased in Ang II-induced THP-1 cells compared with control cells (Fig. 1D). Finally, The role of Ang II in function of macrophage bacterial phagocytosis and digestion was detected by CFU assay. Then function of macrophage bacterial phagocytosis was not significant difference, however the function of macrophage bacterial digestion was obviously decline under Ang II treatment (Fig. 1E).

Ang II stimulation leads to formation and activation of the NLRP3 inflammasome complex in THP-1 cells

The NLRP3 inflammasome is the principal machinery triggering inflammatory responses in macrophages [23]. We next determined whether Ang II can also induce NLRP3 inflammasome production and activation in cultured THP-1 cells by analyzing the colocalization of NLRP3 inflammasome components, the expression of NLRP3 and ASC, the cleavage of pro-caspase- 1 to active caspase- 1 , and the production of IL- $1 \beta$. Ang II concentration-dependently increased the colocalization between NLRP3 (green) and 
A

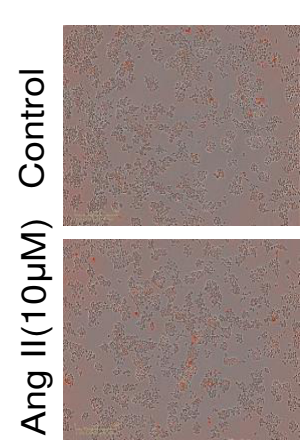

No infected

C

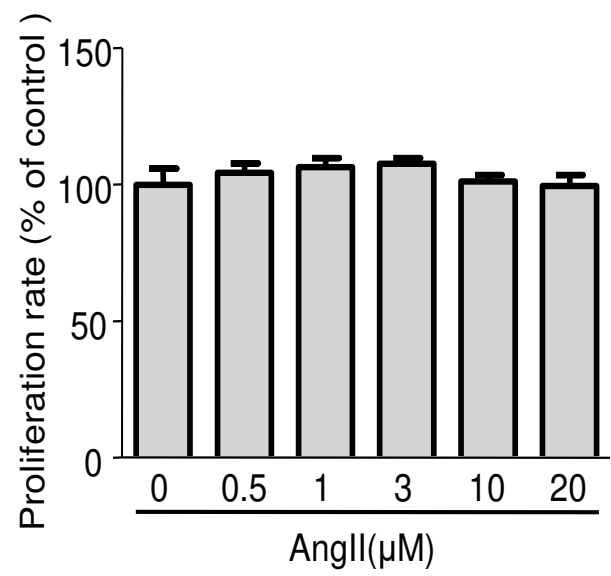

E

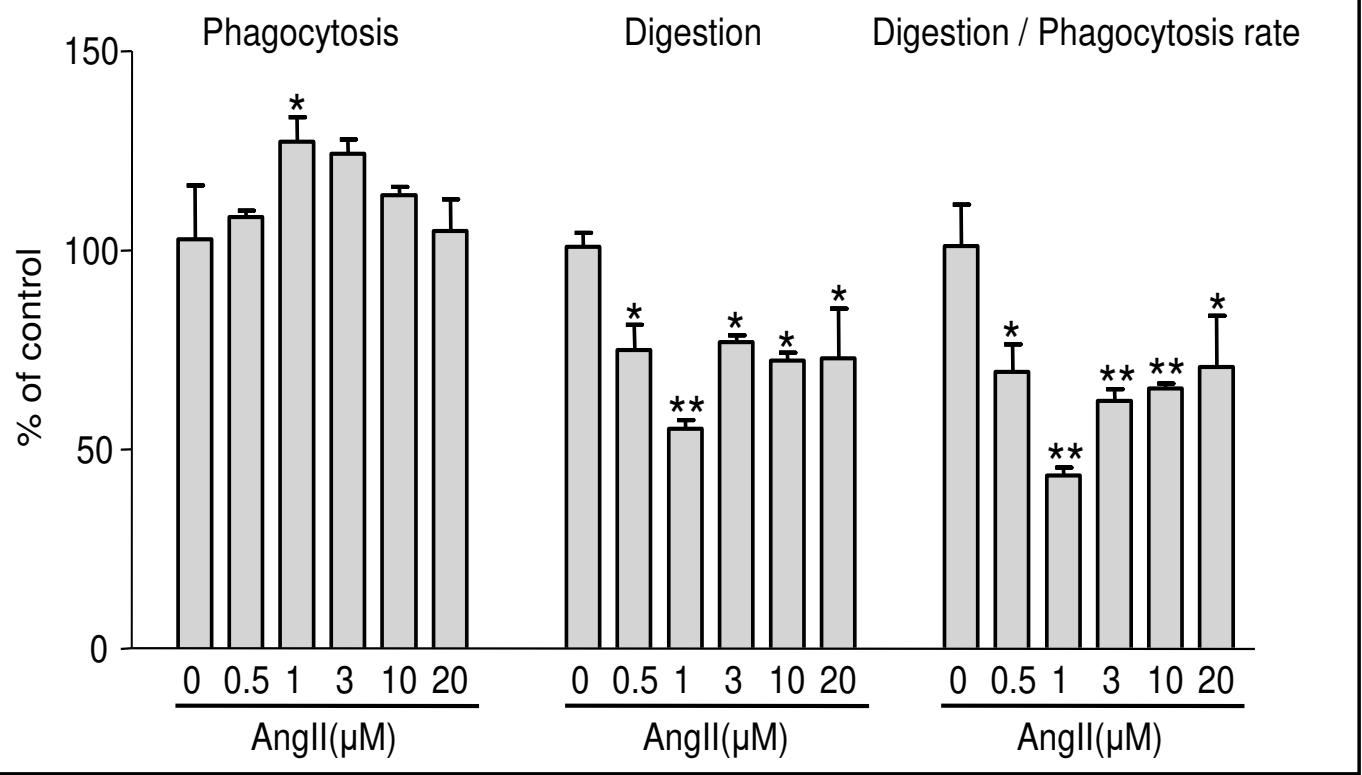

Fig. 1. Ang II treatment affects macrophage digestion function and NO release in THP-1 cells. A and B: Representative images analysis and summarized data showed the cytotoxicity of E.coil (MOI 100) and AngII $(10 \mu \mathrm{M})$ in THP-1 cells for $3 \mathrm{~h}$. C: Summarized data show the proliferation of AngII $(0-20 \mu \mathrm{M})$ on THP-1 cells for 24 h. D: Summarized data show the effect of AngII on NO release in THP-1 cells for 24 h. E: Summarized data show the function of digestion in THP-1 cells with AngII. ${ }^{*} \mathrm{P}<0.05$, ${ }^{* *} \mathrm{P}<0.01$ vs control group. 
Fig. 2. Ang II stimulation leads to formation and activation of the NLRP3 inflammasome complex in THP-1 cells. A: Representative confocal fluorescence images indicating the effect of AngII $(0-20 \mu \mathrm{M} ; 24 \mathrm{~h})$ on the colocalisation of Nlrp3 (Green) with caspase-1 (first line, Red) or with ASC (second line, Red) in THP-1 cells. B and C: Quantitative data of the co-localisation efficiency (Pearson's correlation coefficient) of Nlrp3 with ASC or Nlrp3 with caspase-1. D and E :Western blot analysis and summarized data showed the effect of AngII on the protein expression levels of Nlrp3. F and G: Western blot analysis and summarized data showed the effect of AngII on the protein expression levels of ASC. $\mathrm{H}$ and $\mathrm{I}$ : Western blot analysis and summarized data showed the effect of AngII on the protein expression levels of procaspase-1 (Pro-casp1) and cleaved caspase-1 (Cle-casp1). ${ }^{*} \mathrm{P}<0.05$, $* * \mathrm{P}<0.01$ vs control group.
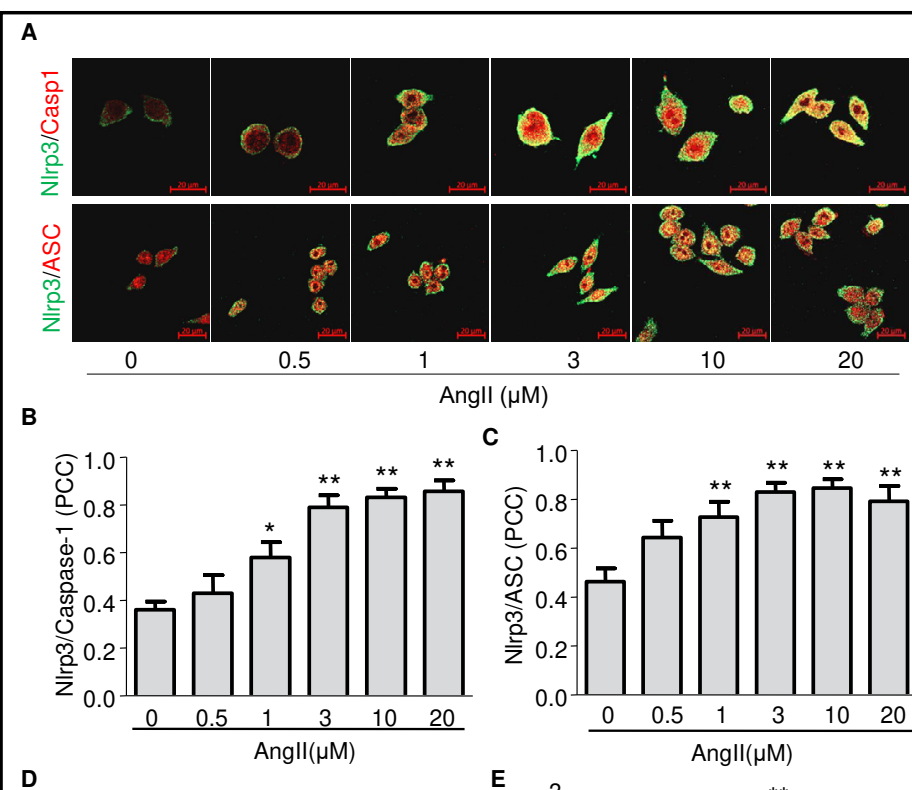

C

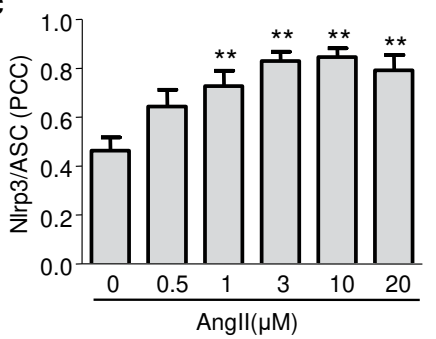

E 3

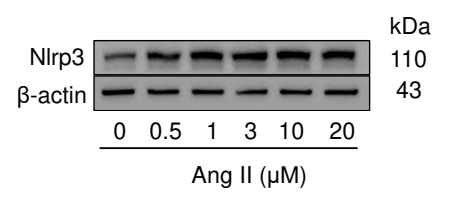

F

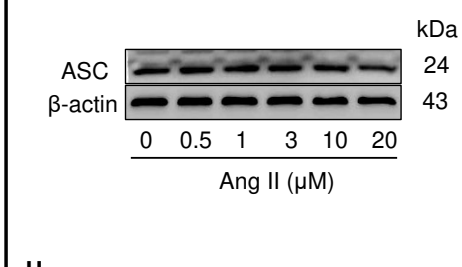

G
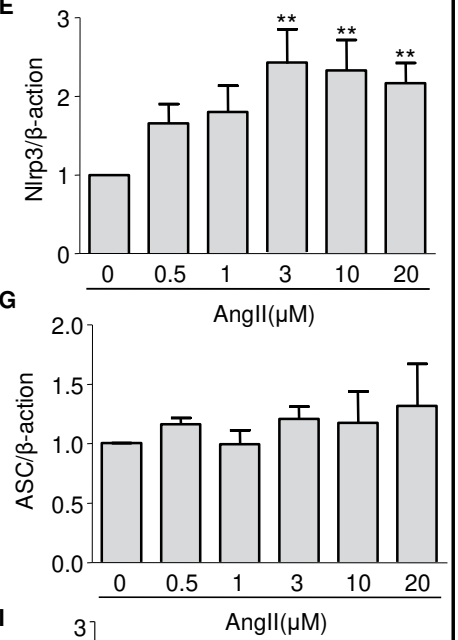

H
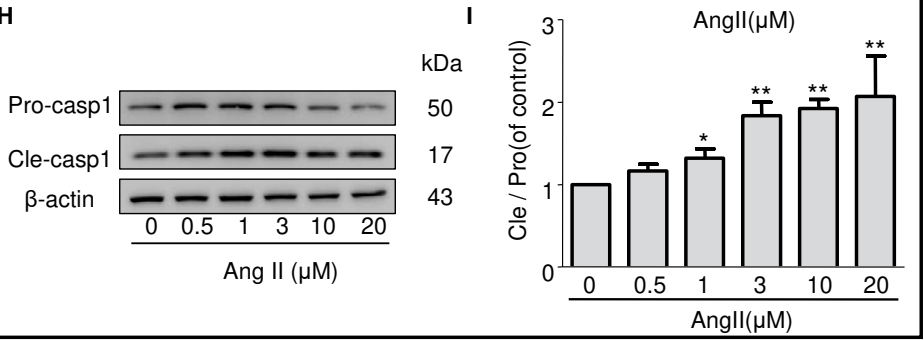

ASC (red), as shown by increased yellow staining and a higher colocalization coefficient (maximal colocalization was observed after Ang II stimulation; Fig. 2A-C). A similar increase in colocalization and the colocalization coefficient was found for NLRP3 and caspase-1 and for NLRP3 and caspase-1.

Consistent with the findings for the formation of the NLRP3 inflammasome complex, we further demonstrated that Ang II affected the expression of the NLRP inflammasome components (Fig. 2D-G) and NLRP3 inflammasome activity in THP-1 cells, as shown by enhanced cleavage of pro-caspase- 1 proteins to their bioactive forms (p20 subunit) (Fig. $2 \mathrm{H}$ and I). Ang II significantly increased NLRP3 expression (Fig. 2D and E). We also noted that Ang II did not increase the transcription or expression of ASC (Fig. 2F and G). Thus, Ang II treatment increased the conversion of inactive pro-caspase- 1 to the active form in THP-1 cells. 
A

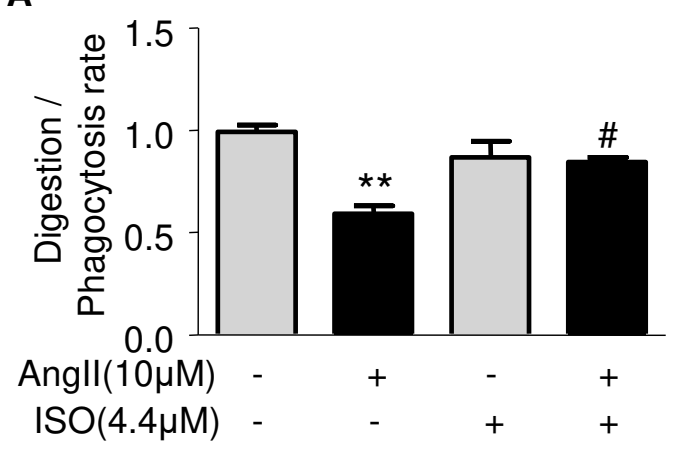

C

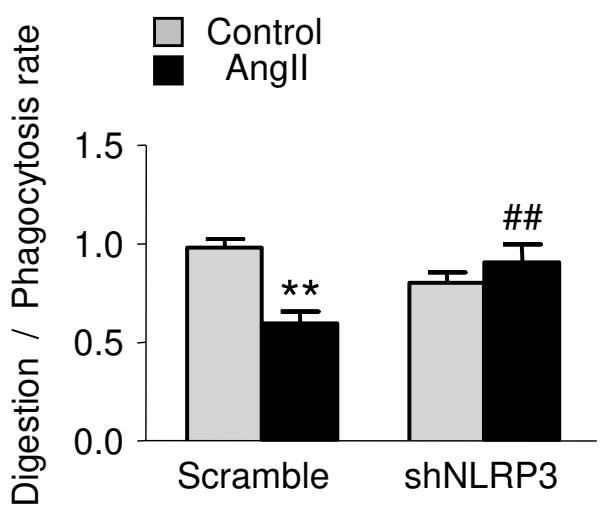

B

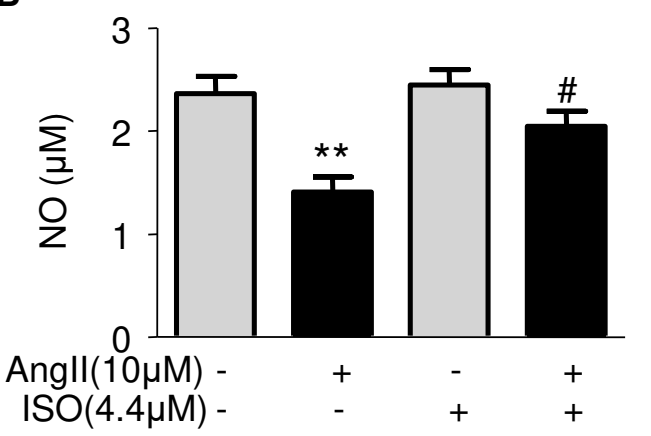

D

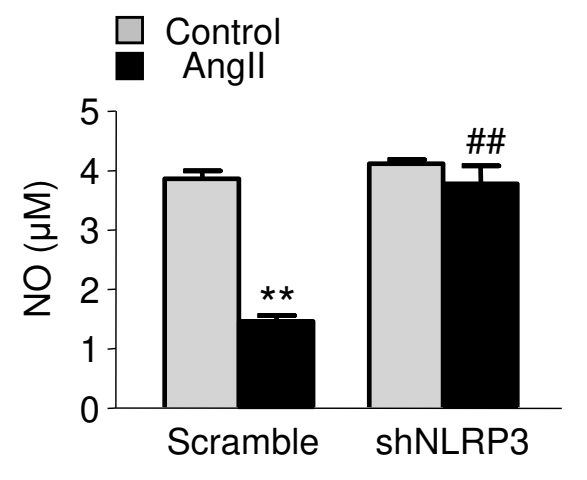

Fig. 3. Effect of Nlrp3 inhibitor or gene silencing on AngII-induced dysfunction of phagocytosis and NO release in THP-1 cells. Differentiated THP-1 macrophages were in the presence of vehicle or Nlrp3 inhibitor (ISO, $4.4 \mu \mathrm{M}$ ) and transfected with scramble or Nlrp3 shRNA plasmids, then stimulated with or without AngII $(10 \mu \mathrm{M})$ for $24 \mathrm{~h}$. A and B: Summarized data show the function of digestion and NO release in THP-1 cells with or without Nlrp3 inhibitor. C and D: Summarized data show the function of digestion and NO release in THP-1 cells with scramble or Nlrp3 shRNA plasmids. ${ }^{*} \mathrm{P}<0.05,{ }^{* *} \mathrm{P}<0.01$ vs control group.

Inhibition of NLRP3 preserves macrophage digestion function

We further examined whether NLRP3 inflammasome activation by Ang II causes macrophage digestion dysfunction in THP-1 cells in vitro. As shown in Fig. 3, NO production and bacteria killing function was damaged with Ang II $(10 \mu \mathrm{M})$ treatment. In contrast, Ang II-induced dysfunction in THP-1 cells was prevented by the NLRP3 inhibitor ISO and in macrophages transfected with NLRP3 shRNA plasmid.

Inhibition of cathepsin B abrogates Ang II-induced NLRP3 inflammasome activation and macrophage digestion dysfunction

To directly monitor the changes in lysosome membrane permeability in live THP-1 cells, the cells were stained with the lysosomotropic agent acridine orange, which emits red fluorescence in undamaged lysosomes and no fluorescence in damaged lysosomes [24]. As shown in Fig. 4A, lysosomes in control cells were visualized as red puncta with high fluorescent intensity, whereas Ang II treatment concentration-dependently decreased the number and fluorescence intensity of red puncta. Lysosomal release of cathepsin B plays a crucial role in mediating NLRP3 inflammasome activation induced by lysosome membrane permeabilization [25]. As shown in Fig. 4A and B, we also found a marked increase in cathepsin B expression in the cytosol of THP-1 cells upon Ang II stimulation, suggesting that cathepsin $\mathrm{B}$ release may be a consequence of increased lysosome membrane permeability leading to NLRP3 inflammasome activation. Similarly, we found that Ca-074 abolished Ang II-induced 


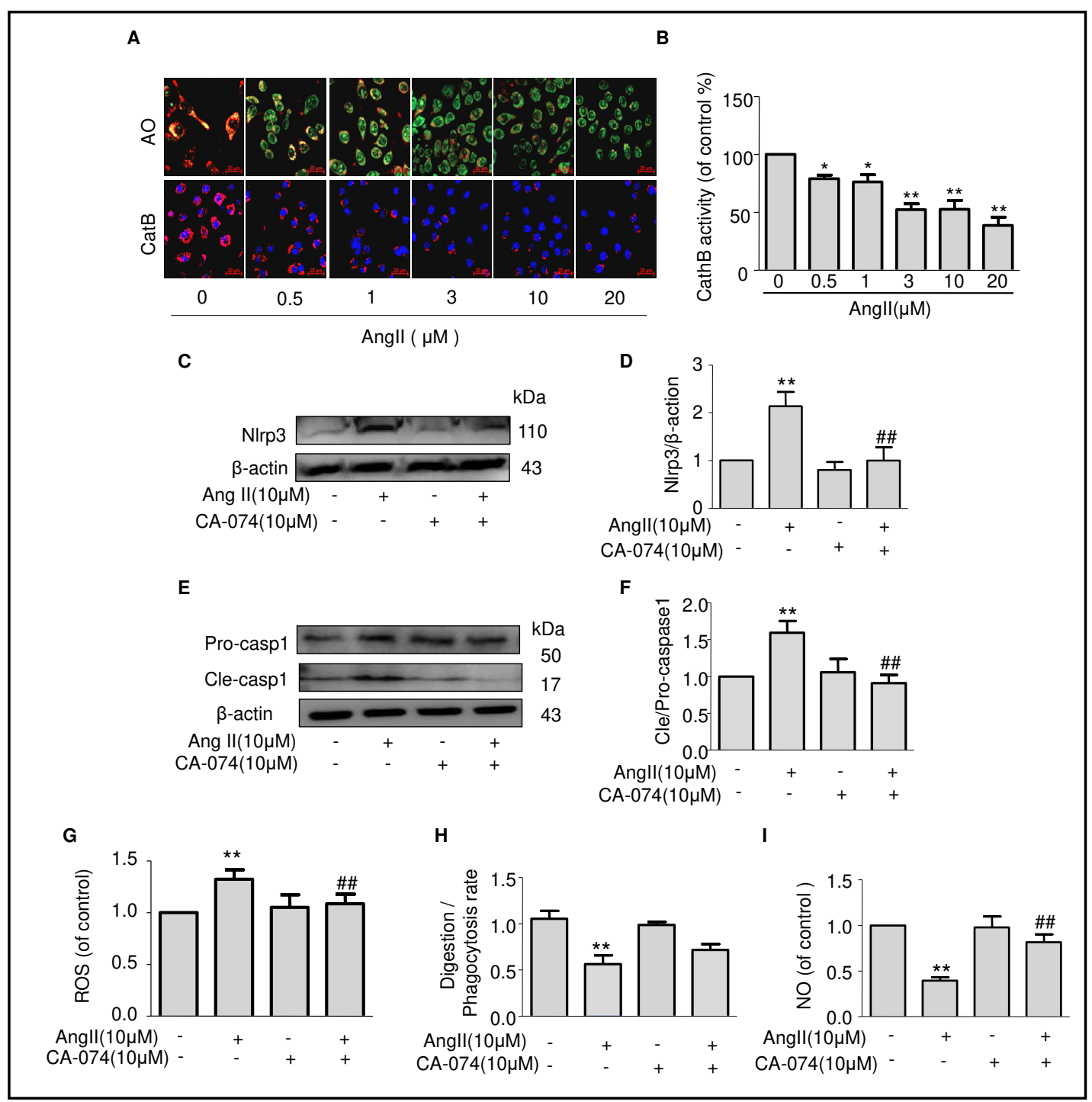

Fig. 4. Inhibition of cathepsin B abrogates Ang II-induced NLRP3 inflammasome activation and macrophage digestion dysfunction. A: Differentiated THP-1 macrophages were incubated in the presence or absence of AngII for $24 \mathrm{~h}$. Confocal microscopy of the cells were stained with acridine orange (upper panels); the fluorescent of cathepsin B activity was stained with z-Arg-Arg-cresyl violet (Red) and nuclei were stained with Hoechst 33258 (Blue). B: Summarized data show the activities of cathepsin-B in THP-1 cells. C-F: Differentiated THP-1 macrophages were treated with or without AngII (10 $\mu \mathrm{M})$ for $24 \mathrm{~h}$ in the presence of vehicle or Cathepsin B inhibitor (CA-074, 10 $\mu \mathrm{M})$. Western blot analysis and summarized data showed the effect of AngII on the protein expression levels of Nlrp3 and Cle/Pro-casp1. G: Quantitative analysis of ROS expression in THP-1 cells were stained with DCFH-DA by flow cytometry. H and I: Summarized data show the function of digestion and NO release in THP- 1 cells. ${ }^{*} \mathrm{P}<0.05,{ }^{* *} \mathrm{P}<0.01$ vs control group.

NLRP3 protein expression and NLRP3 inflammasome activation in THP-1 cells (Fig. 4C-F). These findings confirm that cathepsin B is involved in Ang II-induced macrophage NLRP3 inflammasome activation in vitro. Furthermore, Ca-074 markedly blocked an Ang II-induced increase in ROS and abrogated the bacteria killing and NO release of macrophages (Fig. 4GI). These data suggest that inhibition of cathepsin B also blocks Ang II-induced macrophage digestion dysfunction. 
A

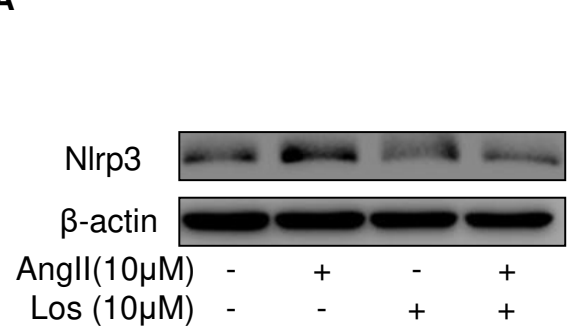

C

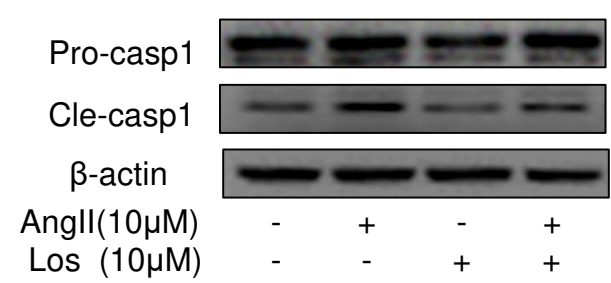

E

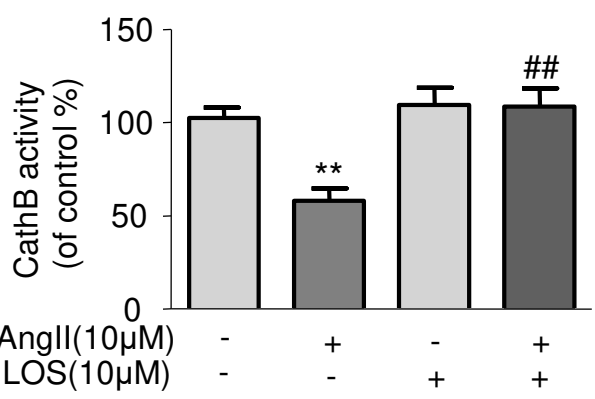

G

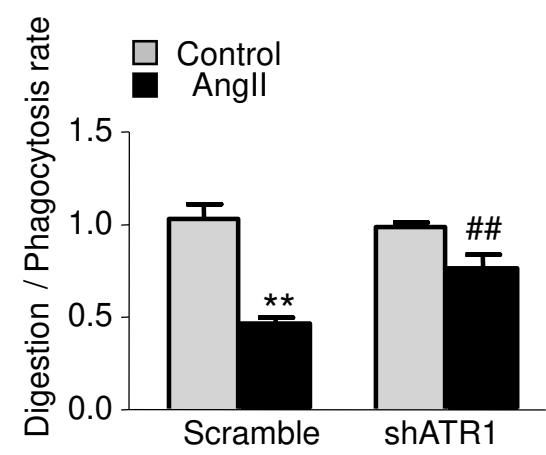

B

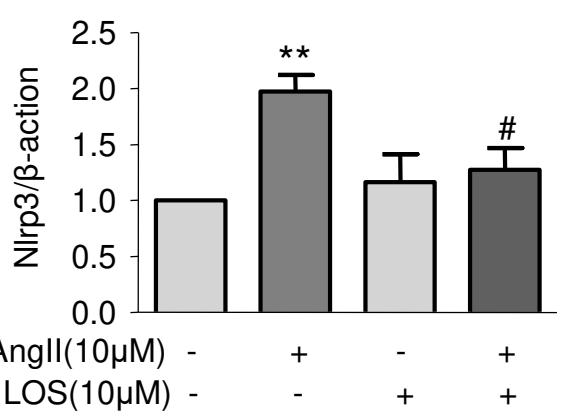

D

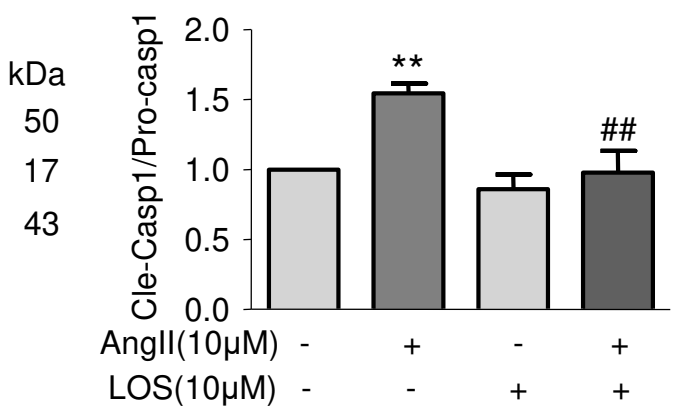

$\mathbf{F}$

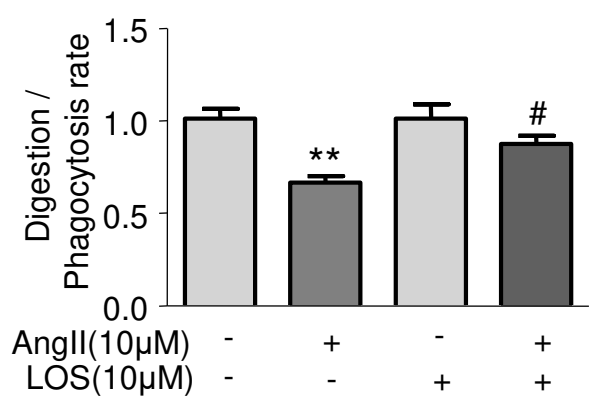

H

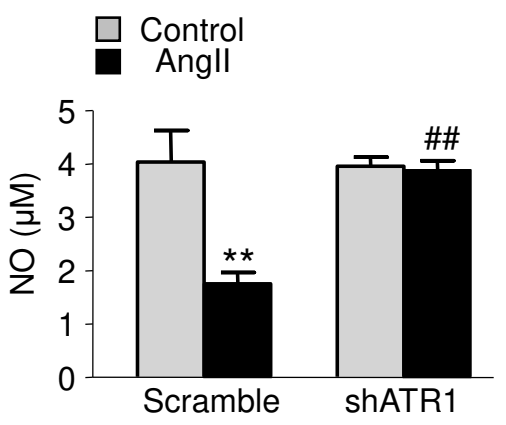

Fig. 5. ATR1 blockade attenuates Ang II-induced macrophage NLRP3 inflammasome activation and digestion dysfunction. The THP-1 cells were in the presence of vehicle or AngII receptor inhibitor (LOS, $10 \mu \mathrm{M}$ ) and transfected with scramble or TIE shRNA plasmids, then stimulated with or without AngII (10 $\mu \mathrm{M}$ ) for 24 h.A-D: Western blot analysis and summarized data showed the treatment effect of LOS on AngIIinduced protein expression levels of Nlrp3 and Cle/Pro-casp1. E: Summarized data show the activities of cathepsin-B in THP-1 cells. F: Summarized data show the function of digestion in THP-1 cells. G and H: Summarized data show the function of digestion and NO release in THP-1 cells with scramble or TIE shRNA plasmids. ${ }^{*} \mathrm{P}<0.05,{ }^{*} \mathrm{P}<0.01$ vs control group. 
A

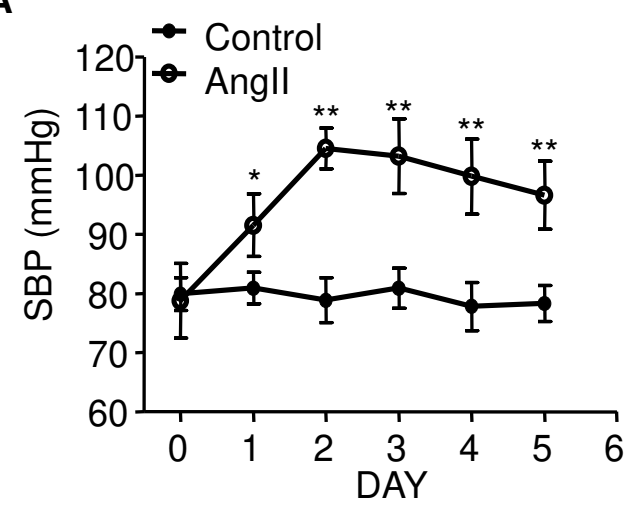

C

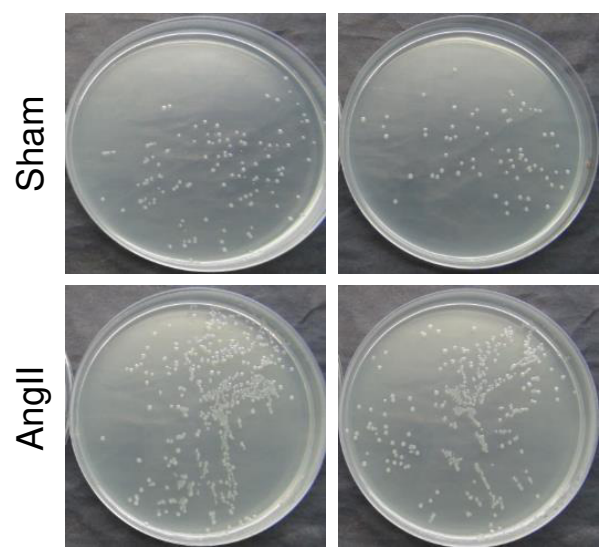

B

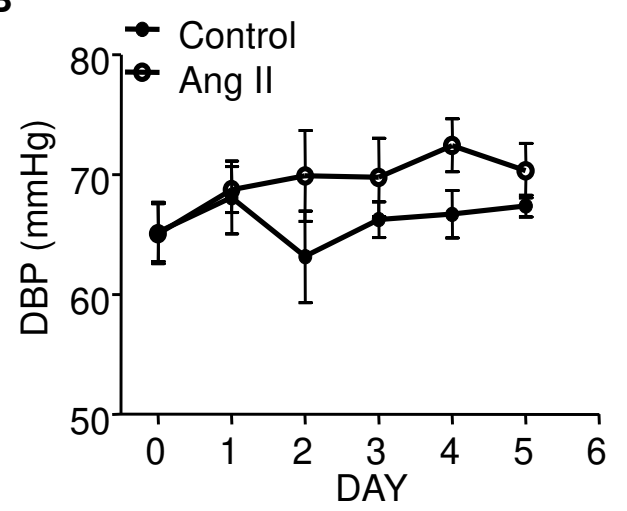

D

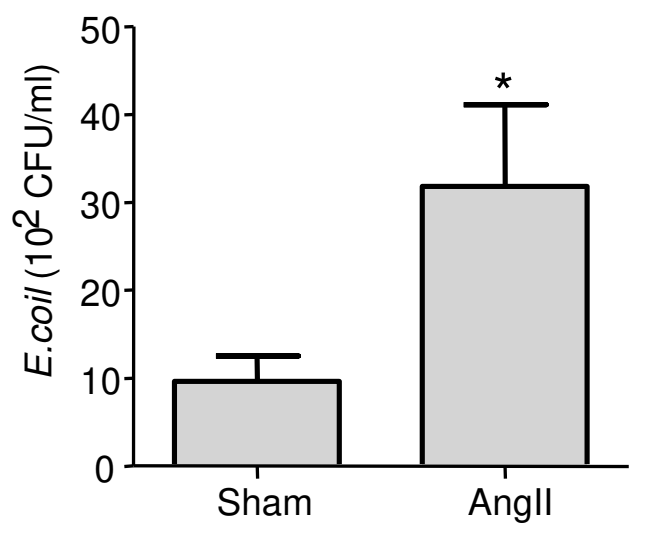

Fig. 6. Macrophage digestion dysfunction is induced in mice treated with Ang II. C57BL/6N mice established sham and hypertension model for 5 days. Then The mice were injected with E.coil and isolated the mononuclear cells . A and B: Summarized data show the systolic blood pressure (SBP) and diastolic blood pressures (DBP). C and D: Representative images analysis and summarized data showed the function of scavenging E.coil in mice. ${ }^{*} \mathrm{P}<0.05,{ }^{* *} \mathrm{P}<0.01$ vs control group.

ATR1 blockade attenuates Ang II-induced macrophage NLRP3 inflammasome activation and digestion dysfunction

The AT receptor is associated with cathepsin activation [26]. To directly determine whether the changes in Ang II-induced macrophage digestion dysfunction by AT receptor caused cathepsin B release-induced NLRP3 inflammasome activation, the Ang II receptor type 1 (ATR1) blocker (LOS) and ATR1 shRNA plasmid transfection were used in THP-1 cells. LOS prevented Ang II-induced caspase- 1 activation but not NLRP3 protein expression (Fig. 5A-D). In addition, cathepsin B release and bacteria killing dysfunction was prevented (Fig. 5E and F). Transfection of THP-1 cells with ATR1 shRNA plasmids also prevented Ang II-induced functional damage and NO release (Fig. 5G and H). Consistently, these data demonstrated that the ATR1 blocker LOS prevents Ang II-induced caspase-1 activation but not NLRP3 protein expression, suggesting that LOS inhibits NLRP3 inflammasome activation in macrophages by disrupting the assembly of the NLRP3 inflammasome complex.

\section{Macrophage digestion dysfunction is induced in mice treated with Ang II}

To further determine the role of Ang II in macrophage digestion dysfunction in mice, hypertension was established by subcutaneous implantation of an osmotic mini-pump delivering Ang II into male mice. After the operation, the model mice showed a sustained elevation in systolic blood pressure and a stable level of $104.5 \pm 3.4 \mathrm{mmHg}$ after the second 
day. However, the diastolic blood pressure was not significantly increased (Fig. 6A and B). On the fifth day, the function of scavenging bacteria was clearly decreased in macrophages from Ang II-induced hypertensive mice (Fig. 6C and D). These findings further indicate that Ang II is involved in the ability of macrophages to digest bacteria.

\section{Discussion}

Recent studies have shown that Ang II can induce an inflammatory response [27] and macrophage dysfunction [28]. However, the cellular physiological relevance of such NLRP3 inflammasome activation in modulating macrophage function remains largely unknown. We aimed to determine whether Ang II-induced NLRP3 inflammasome activation results in macrophage digestion dysfunction. Our data for the first time reveal that activation of NLRP3 inflammasomes by Ang II results in attenuation of the ability of macrophages to digest bacteria, which is closely connected to ATR1-mediated lysosomal dysfunction.

The importance of understanding macrophage function is underscored by consideration of the role of this multifaceted cell type in initiating an inflammatory response against a pathogen. One component central to these functions is digestion. Although macrophage phagocytosis and digestion are a complex process, many studies have illuminated the importance of the mechanisms controlling this function, such as receptor expression, small GTPases, lysosome dysfunction, actin cytoskeleton, and PI3K signaling [29-31]. The function of bacteria clearance is determined by the macrophage rate of digestion and phagocytosis. An increased clearance rate plays a marked role in macrophage physiology, which has been considered a marker event for the attenuation of anti-bacterial effects during infection. The present study revealed that stimulation of macrophages with Ang II decreased the rate of bacterial clearance, without affecting cytotoxicity, proliferation, and phagocytosis (Fig. 1). These data reveal for the first time a critical role for Ang II in inhibiting macrophage bacteria killing.

Our data further confirmed that Ang II inhibition of macrophage bacteria killing is primarily associated with NLRP3 inflammasome formation and activation by macrophages. The NLRP3 inflammasome plays a critical role in the development of different types of chronic diseases, such as vascular diseases, aging, and chronic infections [32-34]. Through various approaches, we confirmed that Ang II stimulation induced the formation and activation of the NLRP3 inflammasome complex in cultured macrophages, as shown using confocal microscopy by colocalization of NLRP3 with ASC or caspase-1 and by biochemical analysis of caspase-1 activity (Fig. 2). These results clearly suggest that NLRP3 inflammasomes are active in macrophages and that Ang II stimulation can lead to their activation. Interestingly, our work found that Ang II inhibited macrophage bacteria killing and NO release; this effect was abolished by NLRP3 gene silencing and NLRP3 inflammasome inhibition with ISO (Fig. 3).

The above research indicated that Ang II induced NLRP3 inflammasome formation and activation in a concentration-dependent manner. Currently, it is generally believed that NLRP3 inflammasome activation requires two signals. Signal 1 of NLRP3 inflammasome activation involves increased NLRP3 gene transcription by NF- $\kappa B$ [35]. Signal 2 of NLRP3 inflammasome activation involves the induced assembly of the NLRP3 inflammasome complex, resulting in activation of caspase- 1 and subsequent pro-IL-1 $\beta$ maturation [36]. Regarding signal 1, Ang II increased the NLRP3 gene transcription and NLRP3 protein expression but did not change the ASC level in this study. As for signal 2, we show for the first time that ROS generation and lysosome stability regulate Ang II activation of the NLRP3 inflammasome and effectuate the macrophage bacteria killing function. Similarly, a recent study demonstrated that the NLRP3 inflammasome is activated by Ang II via the Toll-like receptor 4 (TLR4)/MyD88/NF- $\mathrm{BB}$ pathway in hepatic fibrosis [37]. Nonetheless, our data imply that lysosome stability controls the NLRP3 inflammasome activation and functionality in response to Ang II in macrophages (Fig. 4). The reason for the discrepancy between these 
previous findings and our results for inflammasome activation is unclear. It appears that NLRP3 inflammasome machinery can be activated by distinct mechanisms depending on cell type and pathological condition.

Previous studies have shown that Ang II can regulate cellular responses primarily via the lysosome-associated pathway, leading to pathological cardiac remodeling, by blocking muscle protein wasting, intracellular renin activity, and other cell processes [38, 39]. As a complement, we used Ca-074 to inhibit cathepsin B activation in vitro. Ca-074 significantly attenuated Ang II-induced macrophage bacteria killing dysfunction in macrophages (Fig. 4). Our data suggest that Ang II-induced macrophage bacteria killing dysfunction is mainly associated with cathepsin B-NLRP3 inflammasome signaling in macrophages.

The AT receptor has been associated with cathepsin activation [26]. At the same time, other mechanisms may apply to Ang II-induced cellular disruption by the AT receptor in different cell systems. It should be noted that AT1 and AT2 have been reported to mediate Ang II-induced cellular dysfunction in different cell types [40-42]. Thus, it seems that the interaction of Ang II with AT1 or AT2 can activate different signaling cascades that may lead to distinct functional alterations in cells. Consistently, our data demonstrated that the ATR1 blocker LOS prevents Ang II-induced caspase-1 activation without affecting NLRP3 protein expression, suggesting that LOS inhibits NLRP3 inflammasome activation in macrophages by disrupting the assembly of the NLRP3 inflammasome complex (Fig. 5). Ang II induces ROS production in macrophages by either eliciting $\mathrm{Ca}^{2+}$ and ERK1/2 pathways leading to mitochondrial fission or by activating NADPH oxidases [43]. Interestingly, we found that LOS ameliorated the Ang II-induced macrophage bacteria killing dysfunction (Fig. 5). Similarly, a recent study also demonstrated that LOS has distinct pharmacological effects on different cell types via the ATR1 pathway, such as decreased aortic root dilation by blocking deleterious Ang II-ATR1 signaling, while preserving protective Ang II-ATR1 interactions [44]. Using genetic manipulation of ATR1, we found that ART1 protein expression was significantly reduced after transfection of shRNA into cultured macrophages (data not shown). In the present study, downregulation of the ATR1 gene or LOS significantly prevented Ang II-induced NLRP3 inflammasome formation and activation in macrophages (Fig. 5). Furthermore, our in vivo model system also showed that Ang II attenuates the ability of macrophages to digest bacteria (Fig. 6). To our knowledge, this is the first evidence showing the critical role of the ATR1-cathepsin B-NLRP3 pathway in mediating macrophage activity against a pathogen in response to Ang II stimulation.

\section{Conclusion}

In summary, we demonstrated that activation of NLRP3 inflammasomes by Ang II inhibited macrophage bacteria killing in vitro. In addition, Ang II activated the NLRP3 inflammasome by regulating ROS generation and lysosome stability. In a mouse model of Ang II-induced hypertension, hypertension disrupted macrophage bacteria killing in the blood after treatment of the mice with bacteria. Our results reveal a novel direct action of the macrophage NLRP3 inflammasome on the development of macrophage dysfunction and injury during the early stage of hypertension disorders.

\section{Acknowledgements}

The National Key Research and Development Program of China (No. 2017YFC1700400); The project supported by National Natural Science Foundation of China (NO.81603587, 81603668); Science and Technology Development Plan of Guangdong Province (2017A020211016); Youth Medical Talent Fund of Guangzhou University of Chinese Medicine (QNYC20170105); Science \& Technology Award for Young-aged Talents of China 


\section{Cellular Physiology Cell Physiol Biochem 2018;50:1585-1600 \begin{tabular}{ll|l} 
and Biochemistry Published online: 26 October 2018 & $\begin{array}{l}\text { @ } 2018 \text { The Author(s). Published by S. Karger AG, Basel } \\
\text { www.karger.com/cpb }\end{array}$ \\
\hline
\end{tabular}}

Lian et al.: Angii Induces Macrophage Digestion Dysfunction

Association of Traditional Chinese Medicine (No. CACM-2017-QNRC2-C12); Project of Guangzhou University of Chinese Medicine (No. A1AFD018171Z11020); The Fundamental Research Funds for the Central Universities (No. 11616334).

\section{Disclosure Statement}

No conflicts of interest exist.

\section{References}

Ram CVS: Latest guidelines for hypertension: adopt and adapt. J Am Soc Hypertens 2018;12:67-68. Association AD: 9. Cardiovascular Disease and Risk Management. Diabetes Care 2017;40:S75-S87. Gangwar RS, Rajagopalan S, Natarajan R, Deiuliis JA: Noncoding RNAs in Cardiovascular Disease: Pathological Relevance and Emerging Role as Biomarkers and Therapeutics. Am J Hypertens 2018;31:150165.

4 Davis BK, Wen H, Ting JPY: The Inflammasome NLRs in Immunity, Inflammation, and Associated Diseases. Annu Rev Immunol 2011;29:707-735.

5 He Y, Hara H, Núñez G: Mechanism and Regulation of NLRP3 Inflammasome Activation. Trends Biochem Sci 2016;41:1012-1021.

6 Chen Y, Wang L, Pitzer AL, Li X, Li P-L, Zhang Y: Contribution of redox-dependent activation of endothelial Nlrp3 inflammasomes to hyperglycemia-induced endothelial dysfunction. J Mol Med 2016;94:1335-1347.

7 Ren XS, Tong Y, Ling L, Chen D, Sun HJ, Zhou H, Qi XH, Chen Q, Li YH, Kang YM, Zhu GQ: NLRP3 Gene Deletion Attenuates Angiotensin II-Induced Phenotypic Transformation of Vascular Smooth Muscle Cells and Vascular Remodeling. Cell Physiol Biochem 2017;44:2269-2280.

8 Boini KM, Hussain T, Li PL, Koka S: Trimethylamine-N-Oxide Instigates NLRP3 Inflammasome Activation and Endothelial Dysfunction. Cell Physiol Biochem 2017;44:152-162.

-9 Duewell P, Kono H, Rayner KJ, Sirois CM, Vladimer G, Bauernfeind FG, Abela GS, Franchi L, Nuñez G, Schnurr M, Espevik T, Lien E, Fitzgerald KA, Rock KL, Moore KJ, Wright SD, Hornung V, Latz E: NLRP3 inflammasomes are required for atherogenesis and activated by cholesterol crystals. Nature 2010;464:1357.

10 Rajamaki K, Lappalainen J, Oorni K, Valimaki E, Matikainen S, Kovanen PT, Eklund KK: Cholesterol crystals activate the NLRP3 inflammasome in human macrophages: a novel link between cholesterol metabolism and inflammation. PLoS One 2010;5:e11765.

11 Guyenet PG: The sympathetic control of blood pressure. Nat Rev Neurosci 2006;7:335.

12 Phillips MI, Kagiyama S: Angiotensin II as a pro-inflammatory mediator. Curr opin invest dr (London, England: 2000) 2002;3:569-577.

13 Good RB, Gilbane AJ, Trinder SL, Denton CP, Coghlan G, Abraham DJ, Holmes AM: Endothelial to Mesenchymal Transition Contributes to Endothelial Dysfunction in Pulmonary Arterial Hypertension. Am J Pathol 2015;185:1850-1858.

14 Wenzel P, Rossmann H, Müller C, Kossmann S, Oelze M, Schulz A, Arnold N, Simsek C, Lagrange J, Klemz R, Schönfelder T, Brandt M, Karbach SH, Knorr M, Finger S, Neukirch C, Häuser F, Beutel ME, Kröller-Schön $S$ et al.: Heme oxygenase-1 suppresses a pro-inflammatory phenotype in monocytes and determines endothelial function and arterial hypertension in mice and humans. Eur Heart J 2015;36:3437-3446.

15 te Riet L, van Esch JHM, Roks AJM, van den Meiracker AH, Danser AHJ: Hypertension. Circ Res 2015;116:960.

16 Garcia GE: ANG II receptor antagonists as modulators of macrophages polarization. Am J Physiol-Renal 2010;298:F868-F869.

-17 Clozel M, Kuhn H, Hefti F, Baumgartner HR: Endothelial dysfunction and subendothelial monocyte macrophages in hypertension. Effect of angiotensin converting enzyme inhibition. Hypertension 1991;18:132.

18 Liu H, Semino-Mora C, Dubois A: Mechanism of H. pylori Intracellular Entry: An in vitro Study. Front Cell Infect Mi 2012;2:16. 


\section{Cellular Physiology Cell Physiol Biochem 2018;50:1585-1600

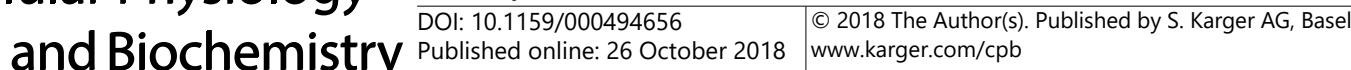

19 Sydow K, Schmitz C, von Leitner E-C, von Leitner R, Klinke A, Atzler D, Krebs C, Wieboldt H, Ehmke H, Schwedhelm E, Meinertz T, Blankenberg S, Böger RH, Magnus T, Baldus S, Wenzel U: Dimethylarginine Dimethylaminohydrolase1 Is an Organ-Specific Mediator of End Organ Damage in a Murine Model of Hypertension. PLOS ONE 2012;7:e48150.

20 Grobe JL, Buehrer BA, Hilzendeger AM, Liu X, Davis DR, Xu D, Sigmund CD: Angiotensinergic Signaling in the Brain Mediates Metabolic Effects of Deoxycorticosterone (DOCA)-Salt in C57 Mice. Hypertension 2011;57:600.

-21 Tsai T-H, Chen S-F, Huang T-Y, Tzeng C-F, Chiang A-S, Kou YR, Lee T-S, Shyue S-K: Impaired Cd14 and Cd36 Expression, Bacterial Clearance, and Toll-Like Receptor 4-Myd88 Signaling in Caveolin-1-Deleted Macrophages and Mice. Shock 2011;35:92-99.

-22 Fang FC: Antimicrobial reactive oxygen and nitrogen species: concepts and controversies. Nat Rev Microbiol 2004;2:820.

23 Jiang Y, Wang M, Huang K, Zhang Z, Shao N, Zhang Y, Wang W, Wang S: Oxidized low-density lipoprotein induces secretion of interleukin- $1 \beta$ by macrophages via reactive oxygen species-dependent NLRP3 inflammasome activation. Biochem and Bioph Res Co 2012;425:121-126.

-24 Niemi K, Teirilä L, Lappalainen J, Rajamäki K, Baumann MH, Öörni K, Wolff H, Kovanen PT, Matikainen S, Eklund KK: Serum Amyloid A Activates the NLRP3 Inflammasome via P2X\&lt;sub\&gt;7\&lt;/sub\&gt; Receptor and a Cathepsin B-Sensitive Pathway. J Immunol 2011;186:6119-6128.

25 Muñoz-Planillo R, Kuffa P, Martínez-Colón G, Smith Brenna L, Rajendiran Thekkelnaycke M, Núñez G: K+ Efflux Is the Common Trigger of NLRP3 Inflammasome Activation by Bacterial Toxins and Particulate Matter. Immunity 2013;38:1142-1153.

26 Pérez-Victoria FJ, Schindler C, Magadán JG, Mardones GA, Delevoye C, Romao M, Raposo G, Bonifacino JS, Linstedt A: Ang2/Fat-Free Is a Conserved Subunit of the Golgi-associated Retrograde Protein Complex. Mol Biol Cell 2010;21:3386-3395.

-27 Suzuki Y, Ruiz-Ortega M, Lorenzo O, Ruperez M, Esteban V, Egido J: Inflammation and angiotensin II. Int J Biochem Cell B 2003;35:881-900.

28 Dinh QN, Drummond GR, Sobey CG, Chrissobolis S: Roles of Inflammation, Oxidative Stress, and Vascular Dysfunction in Hypertension. BioMed Res Int 2014;2014:11.

29 Underhill DM, Ozinsky A: Phagocytosis of Microbes: Complexity in Action. Annu Rev Immunol 2002;20:825-852.

30 Greenberg S, Grinstein S: Phagocytosis and innate immunity. Curr Opin Immunol 2002;14:136-145.

-31 Schlam D, Bagshaw RD, Freeman SA, Collins RF, Pawson T, Fairn GD, Grinstein S: Phosphoinositide 3-kinase enables phagocytosis of large particles by terminating actin assembly through Rac/Cdc42 GTPaseactivating proteins. Nat Commun 2015;6:8623.

-32 Abderrazak A, Syrovets T, Couchie D, El Hadri K, Friguet B, Simmet T, Rouis M: NLRP3 inflammasome: From a danger signal sensor to a regulatory node of oxidative stress and inflammatory diseases. Redox Bio 2015;4:296-307.

-33 Liu W, Zhang X, Zhao M, Zhang X, Chi J, Liu Y, Lin F, Fu Y, Ma D, Yin X: Activation in M1 but not M2 Macrophages Contributes to Cardiac Remodeling after Myocardial Infarction in Rats: a Critical Role of the Calcium Sensing Receptor/NRLP3 Inflammasome. Cell Physiol Biochem 2015;35:2483-2500.

-34 Zhang Q, Wu D, Yang Y, Liu T, Liu H: Dexmedetomidine Alleviates Hyperoxia-Induced Acute Lung Injury via Inhibiting NLRP3 Inflammasome Activation. Cell Physiol Biochem 2017;42:1907-1919.

-35 Bauernfeind FG, Horvath G, Stutz A, Alnemri ES, MacDonald K, Speert D, Fernandes-Alnemri T, Wu J, Monks BG, Fitzgerald KA, Hornung V, Latz E: Cutting Edge: NF-кB Activating Pattern Recognition and Cytokine Receptors License NLRP3 Inflammasome Activation by Regulating NLRP3 Expression. J Immunol 2009;183:787-791.

36 Jin C, Flavell RA: Molecular Mechanism of NLRP3 Inflammasome Activation. J Clin Immunol 2010;30:628631.

37 Cai S-M, Yang R-Q, Li Y, Ning Z-W, Zhang L-L, Zhou G-S, Luo W, Li D-H, Chen Y, Pan M-X, Li X: Angiotensin-(1-7) Improves Liver Fibrosis by Regulating the NLRP3 Inflammasome via Redox Balance Modulation. Antioxid Redox Sig 2016;24:795-812.

-38 Rüster C, Wolf G: Renin-Angiotensin-Aldosterone System and Progression of Renal Disease. J Am Soc Nephrol 2006;17:2985-2991. 


\section{Cellular Physiology Cell Physiol Biochem 2018;50:1585-1600

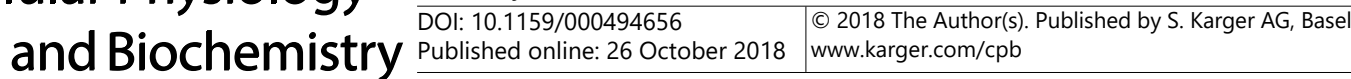

Lian et al.: Angii Induces Macrophage Digestion Dysfunction

39 Chang Y, Li Y, Ye N, Guo X, Li Z, Sun G, Sun Y: Atorvastatin inhibits the apoptosis of human umbilical vein endothelial cells induced by angiotensin II via the lysosomal-mitochondrial axis. Apoptosis 2016;21:977996.

40 Lobov IB, Brooks PC, Lang RA: Angiopoietin-2 displays VEGF-dependent modulation of capillary structure and endothelial cell survival \&lt;em\&gt;in vivo\&lt;/em\&gt. P Natl Acad Sci 2002;99:11205-11210.

41 Scott BB, Zaratin PF, Gilmartin AG, Hansbury MJ, Colombo A, Belpasso C, Winkler JD, Jackson JR: TNF- $\alpha$ modulates angiopoietin-1 expression in rheumatoid synovial fibroblasts via the NF- $\mathrm{BB}$ signalling pathway. Biochem Bioph Res Co 2005;328:409-414.

-42 Hu B, Cheng S-Y: Angiopoietin-2: Development of inhibitors for cancer therapy. Curr Oncol Rep 2009;11:111-116.

43 Flannery PJ, Spurney RF: Transactivation of the Epidermal Growth Factor Receptor by Angiotensin II in Glomerular Podocytes. Nephron Exp Nephrol 2006;103:e109-e118.

-44 Sellers SL, Milad N, Chan R, Mielnik M, Jermilova U, Huang PL, de Crom R, Hirota JA, Hogg JC, Sandor GG, Van Breemen C, Esfandiarei M, Seidman MA, Bernatchez P: Inhibition of Marfan Syndrome Aortic Root Dilation by Losartan: Role of Angiotensin II Receptor Type 1-Independent Activation of Endothelial Function. Am J Pathol 2018;188:574-585. 